\title{
A Review of Delegation and Break-Glass Models for Flexible Access Control Management
}

\author{
Sigrid Schefer-Wenzl ${ }^{1,2}$, Helena Bukvova ${ }^{2}$, and Mark Strembeck ${ }^{2}$ \\ 1 Competence Center for IT-Security \\ University of Applied Sciences Campus Vienna, Austria \\ sigrid.schefer-wenzl@fh-campuswien.ac.at \\ 2 Institute for Information Systems, New Media Lab \\ WU Vienna, Austria \\ \{firstname.lastname\}@wu.ac.at
}

\begin{abstract}
Access control models provide an important means for the systematic specification and management of the permissions in a business information system. While a number of well-known access control models exists (such as the role-based access control model, for example), standard access control models are often not suited for handling exceptional situations. In this context, the demand to increase the flexibility of access management has especially been approached via the development of delegation models and break-glass models. This paper presents the results of a literature review for 329 delegation and break-glass approaches. We give an overview on the existing body of scientific literature in these two areas and compare 35 selected approaches in detail. In our literature review, we revealed different ways of providing delegation and break-glass concepts in general as well as in the context of business process management. Moreover, we identified different sub-topics that have not yet been addressed in detail and thus provide opportunities for future research.
\end{abstract}

Key words: Access Control; Break-Glass; Business Processes; Delegation

\section{Introduction}

Process-aware business information systems can be configured via process models that define all expected execution paths for each business process (see, e.g., 44]). In this context, corresponding access control models specify which subjects are authorized to perform the tasks that are included in the business processes (see, e.g., [43, 45]). While such an approach is well suited for process instances that conform to one of the expected (and therefore pre-defined) execution scenarios, we encounter problems when dealing with exceptional situations, e.g. when no authorized subject is available to execute a particular task in case of emergency (see, e.g., [35, 47]).

This is because traditional access control policies, such as role-based access control (RBAC) (see, e.g., [15, 30]), often cannot be configured to adequately address exceptional and unpredictable situations. However, in a real-world system it is sometimes necessary for subjects to perform tasks they are usually not permitted to perform. For example, in case of an employee's unplanned temporary absence certain tasks need to be maintained by other subjects. In a hospital context, a junior physician should be able to perform certain tasks of a senior physician in case of emergency.

Delegation and break-glass policies provide two well-established mechanisms that help to increase the flexibility of access control mechanisms, while at the same time maintaining a certain security level. Delegation policies enable subjects to transfer their tasks, duties, or roles to another subject (see, e.g., [13, 28, 36]). Subsequently, a subject 
receiving a delegation (the delegatee) will act on behalf of the delegating subject (the delegator). Break-glass policies (see, e.g., [17, 26, 33]) have been introduced to flexibly handle emergency situations by breaking or overriding the standard access permissions in a controlled manner. In essence, a break-glass policy allows a subject to perform an action under certain conditions even though he/she was not previously authorized to do so. Usually, such override accesses are monitored and documented for later reviews and audits. Due to an increasing interest in flexible access management, a variety of different approaches was published offering different features for different application domains. However, the increasing number of such approaches also makes it difficult for organizations to select an approach that fits their needs. Similarly, researchers in this domain may find it challenging to keep an overview of existing literature.

The contribution of this paper is threefold. First, we provide a state-of-the art overview of approaches for delegation and break-glass policies. We present a survey of 329 publications in this research area, providing insight into the development of this field and showing its emerging importance. Second, we compare different approaches for delegation and break-glass policies, distinguishing in particular between approaches that are concerned with delegation and break-glass in general and approaches concerned explicitly with the special demands of these concepts in the context of business processes and workflows. Third, by comparing approaches from selected key articles in detail we provide a foundation for the informed selection of suitable delegation and break-glass models as well as for evaluating future research in this area.

The remainder of this paper is structured as follows. Section 2 presents a survey of the research area. In Sections 3 and 4 a classification and in-depth analysis of existing delegation and break-glass models is introduced. Finally, Section 5 gives a conclusion and outlook on future work.

\section{Development of the Research Area}

In order to identify relevant delegation and break-glass models, we have carried out a literature review based on the guidelines presented, for example, in [6, 25, 48. We have searched seven databases and digital libraries that index scientific articles in information systems and computer science. In particular, our search included the following libraries: ACM Digital Library, IEEE Digital Library, Springer Link, AIS Electronic Library, CiteSeerX Scientific Literature Digital Library, and DBLP. The databases were searched for articles containing in their full-text at least one of our selected search terms.

Based on our previous knowledge of the research area as well as on screening searches, we have picked the following search terms: "break-glass", "break-the-glass", and "delegation" to find articles focusing on delegation or break glass; "access control", "emergency", "flexibility", "workflow", and "business process" to find articles addressing approaches for flexible access control in business-process environments and/or for emergency scenarios. The search results from all databases were combined and doubleentries eliminated. The full-text of the articles was then checked in order to ascertain that the articles fulfill the inclusion criterion: presentation or active discussion of a model for delegation or break-glass procedures. Publications that did not present original research in this area were removed, leaving a sample of 329 publications dealing with delegation (268 articles) and break-glass (61 articles) models.

After screening the sample we noted the broad selection of articles, originating from different research areas (e.g., health care, access control, workflow management), as well as strong interdependencies (cross-references) among the articles. Hence, we 
have decided not to do a further backward reference search, as it was likely to be very broad and complex, while at the same time bringing hardly any new approaches into the sample (see [24]).

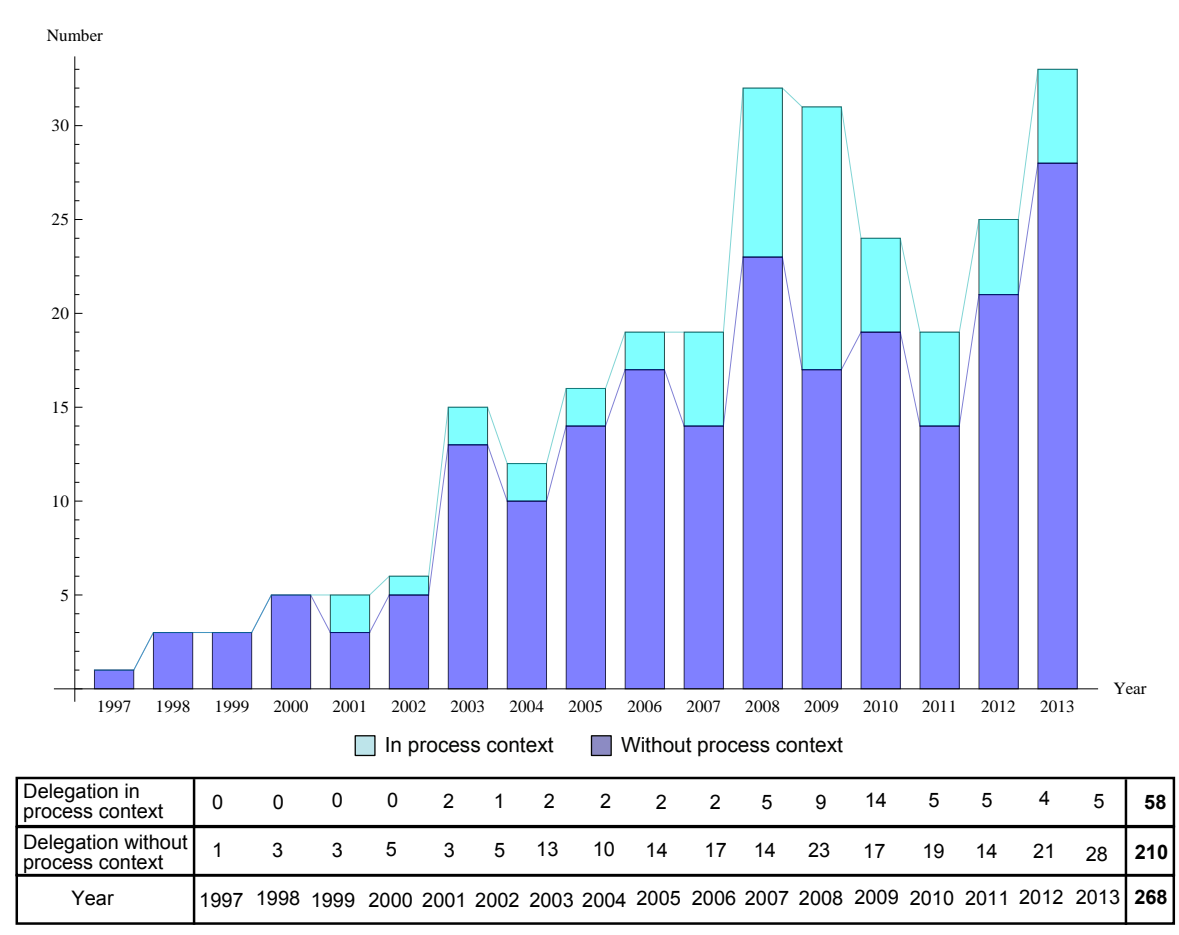

Fig. 1. Development of the delegation research topic

The 329 scientific contributions in the sample reflect the current knowledge base on the two research topics. After reviewing these approaches, we have decided to further categorize the sample (besides distinguishing delegation and break-glass related research) into publications explicitly considering the business process context and publications that discuss break-glass or delegation in general. Fig. 1 and Fig. 2 visualize the structure of the sample with regard to the yearly publication output.

The first comprehensive delegation models were published in the late 90s (see Fig. 11. These publications then mainly focussed on certificate- and attribute-based delegation models. The amount of publications per year increased constantly with the popularity of role-based access control. Delegation models considering a business process/workflow context were first published in 2001 (see Fig. 1). Again the number of published models increased every year with a significant peak in 2009, remaining rather constant since then.

In comparison, a considerably lower amount of break-glass models has been published. The term "break-glass" model, referring to a comprehensive approach for the controlled override of access control rules, first appears in 2006. However, different earlier publications used other terms for similar models (see Fig. 2). The number of publications constantly increased since 2006, with little peaks in 2010 and 2013. In addition, in many years only one or two articles were published considering break-glass models in a business process context. Overall, the increasing total amount of published 


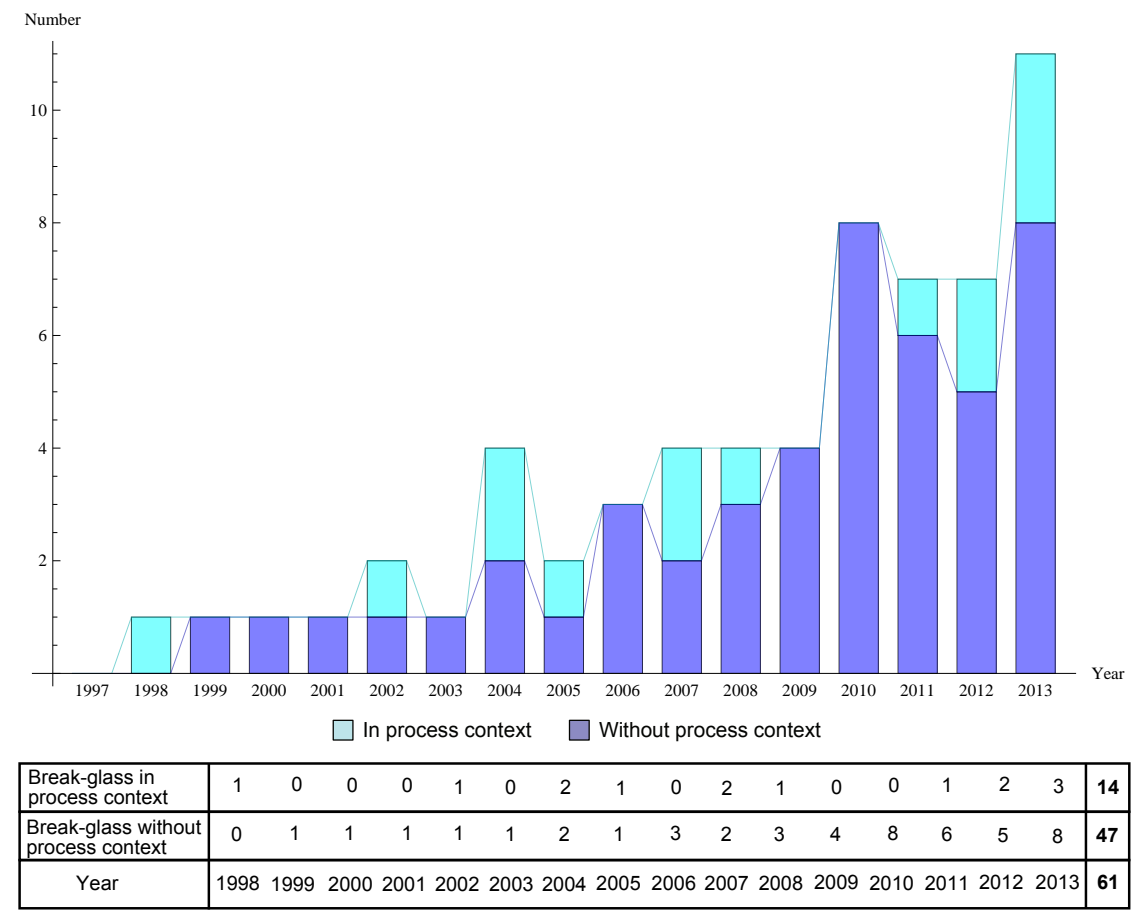

Fig. 2. Development of the break-glass research topic

delegation and break-glass models over the past few years demonstrates the increasing interest in these topics.

By reviewing the approaches in detail, we identified a number of differences. For example, some of these approaches only allow for the delegation of complete roles (see, e.g., [4, 5, 49]), others also allow for permission-based delegation (see, e.g., 23, 41, 50]). Similarly, some break-glass approaches allow for the definition of break-glass policies for individual subjects (subject-based break-glass policies, see, e.g., 1, 29, 34]), others allow for the definition of break-glass policies on role-level (role-based break-glass policies, see, e.g., [7, 16, 45]). In addition, some of the delegation and break-glass models explicitly address entailment constraints (see, e.g., 39, 42, 45]). Entailment constraints define additional conditions for access control decisions by considering, e.g., the task history or certain context information (such as time or location). The most prominent examples of entailment constraints are separation of duty (SOD) and binding of duty (BOD) constraints. A SOD constraint defines that two permissions/tasks must not be assigned to (or activated/performed by) the same subject, while a BOD constraint defines that two bound permissions/tasks need to be assigned to the same subject or role. Furthermore, some approaches offer modeling support to visualize the respective concepts, some approaches (also) provide corresponding tool support for enforcing delegation or break-glass policies (see, e.g., [37, 38, 42]). This variety presents a challenge for researchers working in this field or wishing to quickly grasp the state of research.

To provide a better overview of the existing approaches, we have thus further focused our study by selecting a sub-sample of 35 articles that explicitly aim to evolve approaches for systematic delegation or break-glass procedures. In the subsequent sections, we present an analysis of these approaches by describing for each approach the policy type supported, the context where the approach can be applied, its main features, the types of constraints supported, and which kind of modeling support is 
provided. In particular, Section 3 provides a comparison of delegation, and Section 4 presents a comparison of break-glass approaches.

\section{Comparison of Delegation Approaches}

Fig. 3 and Fig. 4 summarize the results of our comparison of approaches which are concerned with delegation models for roles, permissions, tasks, and duties in an access control or business process context.

In recent years, there has been much work on various aspects of role-based and permission-based delegation. In [5, Barka and Sandhu present RBDM, a framework for characterizing role-based delegation models. RBDM distinguishes, for instance, between permanent or temporary, partial or total, and single- or multi-step delegation. A formal model and some extensions for RBDM are presented in [4. RDM2000 [49] is an extension of RBDM supporting role-based and multi-step delegation. Furthermore, a rule-based declarative language is proposed to specify and enforce policies, separation of duty constraints are considered, and corresponding tool support is provided.

\begin{tabular}{|c|c|c|c|c|c|}
\hline & $\begin{array}{l}\text { Policy } \\
\text { type }\end{array}$ & Context & $\begin{array}{c}\text { Main } \\
\text { Features }\end{array}$ & Constraints & $\begin{array}{l}\text { Modeling } \\
\text { support }\end{array}$ \\
\hline $\begin{array}{l}\text { Barka and } \\
\text { Sandhu } \\
{[4,5]}\end{array}$ & Delegation & RBAC & \begin{tabular}{|l|} 
Delegation of roles \\
\end{tabular} & & formal metamodel \\
\hline $\begin{array}{l}\text { Zhang et al. } \\
\text { [49] }\end{array}$ & Delegation & RBAC & \begin{tabular}{|l|} 
Delegation of roles \\
\end{tabular} & SOD & \begin{tabular}{|l|} 
formal metamodel \\
tool support \\
\end{tabular} \\
\hline $\begin{array}{l}\text { Zhang et al. } \\
{[50] \text {, }} \\
\text { Shang and } \\
\text { Wang [41] }\end{array}$ & Delegation & RBAC & \begin{tabular}{|l|} 
Delegation of roles \\
$\begin{array}{l}\text { Delegation of } \\
\text { permissions }\end{array}$ \\
Conflict detection \\
\end{tabular} & SOD & formal metamodel \\
\hline $\begin{array}{l}\text { Hasebe } \\
\text { et al. [23] }\end{array}$ & Delegation & RBAC & \begin{tabular}{|l|} 
Delegation of roles \\
$\begin{array}{l}\text { Delegation of } \\
\text { permissions }\end{array}$ \\
\end{tabular} & & formal metamodel \\
\hline $\begin{array}{l}\text { Sohr et al. } \\
{[42]}\end{array}$ & Delegation & $\overline{R B A C}$ & \begin{tabular}{|l|} 
Delegation of roles \\
$\begin{array}{l}\text { Delegation of } \\
\text { permissions }\end{array}$ \\
\end{tabular} & SOD & UML \\
\hline $\begin{array}{l}\text { Cole et al. } \\
\text { [11] }\end{array}$ & Delegation & Obligations & \begin{tabular}{|l|}
$\begin{array}{l}\text { Delegation of } \\
\text { obligations }\end{array}$ \\
\end{tabular} & & \\
\hline $\begin{array}{l}\text { Schaad and } \\
\text { Moffett [36] }\end{array}$ & Delegation & \begin{tabular}{|l|} 
Obligations \\
\end{tabular} & \begin{tabular}{|l|}
$\begin{array}{l}\text { Delegation of } \\
\text { obligations }\end{array}$ \\
\end{tabular} & & formal metamodel \\
\hline \multirow{2}{*}{$\begin{array}{l}\text { Ghorbel- } \\
\text { Talbi et al. } \\
{[21,22]}\end{array}$} & \multirow[t]{2}{*}{ Delegation } & \begin{tabular}{|l|} 
RBAC \\
\end{tabular} & Delegation of roles & & \multirow[t]{2}{*}{ formal metamodel } \\
\hline & & \begin{tabular}{|l|} 
Obligations \\
\end{tabular} & \begin{tabular}{|l|}
$\begin{array}{l}\text { Delegation of } \\
\text { obligations }\end{array}$ \\
\end{tabular} & & \\
\hline
\end{tabular}

Fig. 3. Comparison of delegation models

In [50, a permission-based delegation model (PBDM) is presented which allows for the delegation of roles and permissions. Delegation roles are defined to delegate permissions to a user. Support for entailment constraints is limited to static separation of duty constraints. Furthermore, some delegation-related conflicts are described in [50] - resolutions for these conflicts are not discussed, however. In [41, an extension to PBDM is presented to integrate entailment constraints in permission-based 
delegation. Shang and Wang [41] focus on static separation of duty constraints and shortly address related conflicts. Moreover, they analyze role-based constraints and do not consider task-based constraints. An approach similar to [50] is presented in [23, where a capability-based delegation model (CRBAC) based on RBAC96 (see [30]) is introduced to support cross-domain delegation of roles and permissions in terms of capability transfer. Recently, an approach for the model-based specification of rolebased delegation and revocation policies via UML was introduced in [42. They use standard UML class and object diagrams for graphically visualizing delegation policies. Corresponding tool support as well as conflict detection and resolution handling are not provided in 42 .

In addition to roles and permissions, duties or obligations may also be subject to delegation. Duties usually define actions which must be performed in order to meet legal and/or internal regulations. Yet, the delegation of duties has received little attention in literature so far, although it has been identified as important phenomenon, e.g., in [11, where different ways of delegating obligations are discussed. In [36, the delegation of obligations is addressed, mainly motivating the reasons for delegating obligations and stressing the need for balancing authorizations and obligations. Another basic delegation model for obligations has been introduced in [21, 22. In this approach, different kinds of duty-level and role-level delegations are considered, also taking contextual information into account. Yet, none of the above approaches considers the delegation of duties in a business process context. Similarly, none of the above approaches discusses the delegation of duties/obligations with respect to entailment constraints, corresponding modeling/tool support, or the detection and resolution of related conflicts.

\begin{tabular}{|c|c|c|c|c|c|}
\hline & $\begin{array}{l}\text { Policy } \\
\text { type }\end{array}$ & Context & $\begin{array}{c}\text { Main } \\
\text { Features }\end{array}$ & Constraints & $\begin{array}{l}\text { Modeling } \\
\text { support }\end{array}$ \\
\hline \multirow[t]{2}{*}{$\begin{array}{l}\text { Atluri and } \\
\text { Warner [3] }\end{array}$} & Delegation & \begin{tabular}{|l|}
$\begin{array}{c}\text { Business } \\
\text { processes }\end{array}$ \\
\end{tabular} & \begin{tabular}{|l|} 
Delegation of tasks \\
\end{tabular} & SOD & formal metamodel \\
\hline & & & Conflict detection & & \\
\hline \multirow{2}{*}{$\begin{array}{l}\text { Wainer et } \\
\text { al. [46] }\end{array}$} & Delegation & RBAC & \begin{tabular}{|l|} 
Delegation of roles \\
\end{tabular} & SOD & formal metamodel \\
\hline & & \begin{tabular}{|l|}
$\begin{array}{c}\text { Business } \\
\text { processes }\end{array}$ \\
\end{tabular} & Delegation of tasks & & tool support \\
\hline \multirow{3}{*}{$\begin{array}{l}\text { Crampton } \\
\text { and Khamb- } \\
\text { hammettu } \\
{[12,13]}\end{array}$} & Delegation & RBAC & \begin{tabular}{|l|} 
Delegation of roles \\
\end{tabular} & SOD & formal metamodel \\
\hline & & \begin{tabular}{|l|} 
Business \\
nurocesses
\end{tabular} & \begin{tabular}{|l|} 
Delegation of tasks \\
\end{tabular} & & \\
\hline & & & Conflict detection & & \\
\hline \multirow{2}{*}{$\begin{array}{l}\text { Gaaloul } \\
\text { et al. [18, } \\
19,20]\end{array}$} & Delegation & RBAC & \begin{tabular}{|l|} 
Delegation of roles \\
\end{tabular} & SOD & formal metamodel \\
\hline & & \begin{tabular}{|l|}
$\begin{array}{c}\text { Business } \\
\text { processes }\end{array}$ \\
\end{tabular} & Delegation of tasks & BOD & tool support \\
\hline \multirow{4}{*}{$\begin{array}{l}\text { Schefer- } \\
\text { Wenzl et al. } \\
{[37,40]}\end{array}$} & Delegation & RBAC & Delegation of roles & SOD & formal metamodel \\
\hline & & \begin{tabular}{|l|} 
Business \\
processes
\end{tabular} & Delegation of tasks & $\mathrm{BOD}$ & UML \\
\hline & & & Delegation of duties & & tool support \\
\hline & & & Conflict detection & & \\
\hline
\end{tabular}

Fig. 4. Comparison of delegation models in a business process context

However, delegation in a business-process or workflow context has received considerable attention in recent years (see Section 2 and Fig. 4). In [3], the notion of delegation is extended to allow for conditional delegation. Different types of constraints, 
such as separation of duty constraints, are addressed in the context of delegation. Moreover, three types of conflicts as well as a runtime allocation algorithm are presented. A formal model for role-based and task-based delegation in worklows using the notions of case and organizational unit is described in [46. The detection and resolution of delegation-related conflicts is not discussed in [46 though. Similar approaches without related modeling support and only limited support for conflict detection are also presented in [12, 13. The effects of some delegation operations on three workflow execution models are described in 13 .

Only few contributions exist which consider entailment constraints and related conflicts in the context of delegation. Gaaloul et al. [18, 19, 20] present a formal approach for integrating task delegation into the RBAC model which also considers separation of duty and binding of duty constraints. The approach presented in [18, 19, 20. does not consider the delegation of duties and does not provide a corresponding modeling extension to enable the graphical visualization of process-related delegation concepts. In 12, the satisfiability problem of workflows in the context of constrained delegation is addressed. Crampton and Khambhamettu also provide an algorithm that determines whether to permit a delegation request.

In [37, 40], an approach to model the delegation of roles, tasks, and duties in UML Activity diagrams is introduced. In addition, algorithms are introduced to systematically check for conflicts before delegating tasks, duties, and roles in a business process context at design- and runtime. The approach considers separation of duty and binding constraints and provides resolution strategies to resolve each conflict type (see Fig. 44).

\section{Comparison of Break-Glass Approaches}

In our analysis of break-glass approaches, we distinguish two types of models. First, we have approaches that primarily aim to integrate break-glass policies into (role-based) access control models. Second, a number of different approaches exist that integrate break-glass related information into a business process/workflow environment. Figs. 5 and 6 show an overview of selected break-glass approaches in an access control or business process context.

Several approaches exist to integrate break-glass policies into access control models. For example, the optimistic security principle 29] aims to handle exceptional cases. In the approach from Povey [29, any access is legitimate and is thus granted. Monitoring and recording functions are provided to guarantee traceability. These functions are implemented using the Clark-Wilson model (see [10]). A similar approach is presented by Ardagna et al. 2]. They introduce a break-glass approach where an action can be performed by finding a corresponding emergency policy. Alternatively, a breakglass override can be granted if the system is in an emergency state and a supervisor can be notified about the override. In both approaches, the enforcement of security policies is retrospective. They rely on administrators to detect unreasonable accesses and subsequently take steps to compensate for undesired behavior. For this reason, this approach causes a significant burden for administrators. Moreover, both approaches do not consider entailment constraints and do not provide corresponding tool support.

The break-the-glass RBAC (BTG-RBAC) model [16] specifies for each permissionto-role assignment if a break-glass override is allowed. Moreover, obligations can be associated with permissions to define mandatory actions that must be performed in case of a break-glass override. The BTG-RBAC model does not consider entailment constraints and it does not provide tool support. In [7], a break-glass extension for SecureUML is introduced. The resulting SecureUML break-glass policies can then 


\begin{tabular}{|c|c|c|c|c|c|}
\hline & $\begin{array}{l}\text { Policy } \\
\text { type }\end{array}$ & Context & $\begin{array}{c}\text { Main } \\
\text { Features }\end{array}$ & Constraints & $\begin{array}{l}\text { Modeling } \\
\text { support }\end{array}$ \\
\hline Povey [29] & Break-Glass & \begin{tabular}{|l|} 
Optimistic \\
security
\end{tabular} & \begin{tabular}{|l|}
$\begin{array}{l}\text { subject-specific } \\
\text { break-glass rules }\end{array}$ \\
review mechanism \\
\end{tabular} & & formal metamodel \\
\hline $\begin{array}{l}\text { Ardagna } \\
\text { et al. [2] }\end{array}$ & Break-Glass & \begin{tabular}{|l|}
$\begin{array}{l}\text { Policy } \\
\text { spaces }\end{array}$ \\
\end{tabular} & \begin{tabular}{|l|}
$\begin{array}{l}\text { subject-specific } \\
\text { break-glass rules }\end{array}$ \\
review mechanism \\
\end{tabular} & & $\begin{array}{l}\text { formal metamodel } \\
\text { tool support }\end{array}$ \\
\hline $\begin{array}{l}\text { Ferreira } \\
\text { et al. [16] }\end{array}$ & Break-Glass & RBAC & \begin{tabular}{|l|}
$\begin{array}{l}\text { role-based } \\
\text { break-glass rules }\end{array}$ \\
review mechanism \\
\end{tabular} & & formal metamodel \\
\hline $\begin{array}{l}\text { Brucker and } \\
\text { Petritsch } \\
\text { [7] }\end{array}$ & Break-Glass & $\frac{\text { RBAC }}{\text { XACML }}$ & \begin{tabular}{|l|}
$\begin{array}{l}\text { role-based } \\
\text { break-glass rules }\end{array}$ \\
review mechanism \\
\end{tabular} & SOD & \begin{tabular}{|l|} 
formal metamodel \\
UML tool support
\end{tabular} \\
\hline $\begin{array}{l}\text { Alqatawna } \\
\text { et al. [1] }\end{array}$ & Break-Glass & \begin{tabular}{|l|} 
XACML \\
Obligations
\end{tabular} & \begin{tabular}{|l|}
$\begin{array}{l}\text { subject-specific } \\
\text { break-glass rules }\end{array}$ \\
review mechanism \\
\end{tabular} & & $\begin{array}{l}\text { consistency checks } \\
\text { tool support }\end{array}$ \\
\hline $\begin{array}{l}\text { Rissanen } \\
\text { et al. [33, } \\
\text { 34] }\end{array}$ & Break-Glass & \begin{tabular}{|l|} 
Privilege \\
Calculus
\end{tabular} & \begin{tabular}{|l|}
$\begin{array}{l}\text { subject-specific } \\
\text { break-glass rules }\end{array}$ \\
review mechanism \\
\end{tabular} & & formal metamodel \\
\hline $\begin{array}{l}\text { Carminati } \\
\text { et al. }[8,9]\end{array}$ & Break-Glass & Obligations & \begin{tabular}{|l|}
$\begin{array}{l}\text { subject-specific } \\
\text { break-glass rules }\end{array}$ \\
review mechanism
\end{tabular} & \begin{tabular}{|l|} 
context \\
constraints
\end{tabular} & \begin{tabular}{|l|} 
formal metamodel \\
consistency checks \\
tool support \\
\end{tabular} \\
\hline
\end{tabular}

Fig. 5. Comparison of break-glass models

be transformed into XACML. Furthermore, the model allows for the definition of separation of duty constraints. Another approach for discretionary overriding of access control in XACML policies is introduced in 1 1. In particular, a break-glass policy is specified as an XACML override-obligation, which logs the activity, prompts the user for confirmation, and notifies a (pre-defined) authority. This approach offers subjectspecific break-glass policies, but does not consider entailment constraints. In [33, 34, a certificate-based approach based on the Privilege Calculus Framework is used to implement a break-glass mechanism. The Secure information sharing break-glass model introduced in [8, 9] uses the Core Event Specification Language (CESL) for visualising logical definitions and sequences. This language provides stream, event, and pattern operators to express queries. In comparison to other approaches, emergency policies are only valid temporarily and cannot be triggered by a user but only by the system. Moreover, contextual information is taken into account in access control decisions.

Only few contributions exist to integrate the concept of break-glass policies into a business process context (see Fig. 6). However, such an integration can be very useful, as suggested in [27, for example, where a survey on flexibility criteria for business process management systems is presented. Amongst others, sophisticated exception handling mechanisms are identified as important flexibility requirements for processaware information systems. In [45, Wainer et al. present an RBAC model for workflow systems, called W-RBAC. They also extend this model via exception handling functionalities that allow for the controlled overriding of entailment constraints in case of emergency. To achieve this, each constraint is associated with a certain level of priority. Furthermore, roles hold override privileges according to their level of responsibility. Subject-specific break-glass policies are not supported in the W-RBAC model. 


\begin{tabular}{|c|c|c|c|c|c|}
\hline & $\begin{array}{l}\text { Policy } \\
\text { type }\end{array}$ & Context & $\begin{array}{c}\text { Main } \\
\text { Features }\end{array}$ & Constraints & $\begin{array}{l}\text { Modeling } \\
\text { support }\end{array}$ \\
\hline \multirow{3}{*}{$\begin{array}{l}\text { Wainer et } \\
\text { al. [45] }\end{array}$} & \multirow[t]{3}{*}{ Break-Glass } & RBAC & \multirow{3}{*}{\begin{tabular}{|l|}
$\begin{array}{l}\text { role-specific } \\
\text { break-glass rules }\end{array}$ \\
review mechanism
\end{tabular}} & \multirow[t]{3}{*}{ SOD } & \multirow{3}{*}{\begin{tabular}{|l|} 
formal metamodel \\
tool support \\
\end{tabular}} \\
\hline & & Business & & & \\
\hline & & & & & \\
\hline \multirow{3}{*}{$\begin{array}{l}\text { Reichert } \\
\text { and Dadam } \\
\text { [31] }\end{array}$} & \multirow[b]{2}{*}{ Break-Glass } & \multirow{2}{*}{\begin{tabular}{|c|}
$\begin{array}{c}\text { Business } \\
\text { processes }\end{array}$ \\
\end{tabular}} & & & \multirow{3}{*}{$\begin{array}{l}\text { formal metamodel } \\
\text { tool support }\end{array}$} \\
\hline & & & & & \\
\hline & & & & & \\
\hline \multirow{3}{*}{$\begin{array}{l}\text { Weber } \\
\text { et al. [47] }\end{array}$} & Break-Glass & Business & role-based & & \multirow[t]{3}{*}{ formal metamodel } \\
\hline & & processes & break-glass rules & & \\
\hline & & & review mechanism & & \\
\hline \multirow{2}{*}{$\begin{array}{l}\text { Reichert et } \\
\text { al. [32] }\end{array}$} & Break-Glass & Business & review mechanism & SOD & \multirow{2}{*}{$\begin{array}{l}\text { formal metamodel } \\
\text { consistency checks }\end{array}$} \\
\hline & & processes & & & \\
\hline \multirow{4}{*}{\begin{tabular}{|l|} 
Schefer- \\
Wenzl and \\
Strembeck \\
{$[38,39]$}
\end{tabular}} & \multirow[t]{4}{*}{ Break-Glass } & \multirow{4}{*}{\begin{tabular}{|c|} 
RBAC \\
$\begin{array}{l}\text { Business } \\
\text { processes }\end{array}$ \\
\end{tabular}} & \multirow{2}{*}{$\begin{array}{l}\text { subject-specific } \\
\text { break-glass rules }\end{array}$} & \multirow{4}{*}{\begin{tabular}{|l|} 
SOD \\
BOD
\end{tabular}} & \multirow{4}{*}{\begin{tabular}{|l|} 
formal metamodel \\
Consistency checks \\
tool support \\
UML \\
\end{tabular}} \\
\hline & & & & & \\
\hline & & & review mechanism & & \\
\hline & & & $\begin{array}{l}\text { role-based } \\
\text { break-glass rules }\end{array}$ & & \\
\hline
\end{tabular}

Fig. 6. Comparison of break-glass models in a business process context

Moreover, corresponding modeling support for the visualization of business processes and corresponding break-glass policies is not provided.

Several other approaches exist that deal with process adaptations and process evolutions in order to flexibly handle different types of exceptions in process-aware information systems. For example, 31] provides a formal model to support dynamic structural changes of process instances. A set of change operations is defined that can be applied by users in order to modify a process instance execution path, while maintaining its structural correctness and consistency. In 47, change patterns and change support features are identified and several process management systems are evaluated regarding their ability to support process changes. Exception handling via structural adaptations of process models are also considered in 32. In particular, several correctness criteria and their application to specific process meta models are discussed. Thus, this approach handles exceptional process executions by dynamically adapting the process flow. All these approaches that integrate break-glass policies into business processes have in common that processes must be changed in order to handle exceptional situations. A different approach is presented in [38, 39], where the main goal is to maintain the designed process flow, while ensuring that only authorized subjects are allowed to participate in a workflow. A special focus is on the implications of task-based entailment constraints in exceptional situations. Moreover, [38, 39] also offer modeling and tool support for business processes and related break-glass policies.

\section{Conclusion}

In this paper, we presented a comparison of different delegation and break-glass models that provide means to systematically increase the flexibility of access control models. In particular, we performed a literature review according to the guidelines presented in [6, 25. 48. Based on this literature review, we performed an in-depth review and a detailed discussion of 35 key articles in these areas. The corresponding comparison includes the 
essential characteristics of the different approaches and can provide decision support for practitioners and researchers when selecting one of these approaches.

Moreover, our work shows that the demand for increasing the flexibility of access control (in general as well as in a business process context) will remain a lively and important research topic for years to come. So far, break-glass models have been researched to a lesser extent than delegation models. However, our literature review shows that break-glass approaches especially attract attention in application domains with high demands for a seamless, uninterrupted system operation, such as hospitals for example. Moreover, some approaches aim to combine delegation and break-glass mechanisms, e.g., by allowing automatic delegation in case of emergency [14.

In addition, it can be noted that so far access control in a business process context has received less attention in the scientific literature. This fact may be due to an increased complexity that results from the combination of process flows with corresponding access control policies and access control constraints (such as entailment constraints for example). However, given the importance of the process-oriented approaches, additional research in this area would be of high relevance.

In our literature review, we found that in many approaches formal metamodels are a key research artefact to integrate delegation and break-glass concepts with access control models. In contrast, visual modelling support (e.g., via respective UML extensions) or corresponding tools were rarely presented though. This fact could make some of the approaches difficult to use and implement in practice. The limited research with regard to delegation and break-glass in business processes as well as the lack of modeling support and tool support are relevant directions for further research.

\section{References}

1. J. Alqatawna, E. Rissanen, and B. Sadighi. Overriding of Access Control in XACML. In Proc. of the8th IEEE International Workshop on Policies for Distributed Systems and Networks, 2007.

2. C. A. Ardagna, S. D. C. di Vimercati, S. Foresti, T. W. Grandison, S. Jajodia, and P. Samarati. Access control for smarter healthcare using policy spaces. Computers \& Security, 29(8), 2010.

3. V. Atluri and J. Warner. Supporting conditional delegation in secure workflow management systems. In Proc. of the10th ACM symposium on Access control models and technologies (SACMAT), 2005.

4. E. Barka and R. Sandhu. A Role-Based Delegation Model and Some Extensions. In Proc. of the 23rd National Information Systems Security Conference, 2000.

5. E. Barka and R. Sandhu. Framework for Role-Based Delegation Models. In Proc. of the 16th Annual Computer Security Applications Conference, 2000.

6. P. Brereton, B. A. Kitchenham, D. Budgen, M. Turner, and M. Khalil. Lessons from applying the systematic literature review process within the software engineering domain. Journal of Systems and Software, 80(4), 2007.

7. A. D. Brucker and H. Petritsch. Extending Access Control Models with Break-Glass. In Proc. of the 14th ACM symposium on Access control models and technologies (SACMAT), 2009.

8. B. Carminati, E. Ferrari, and M. Guglielmi. Secure information sharing on support of emergency management. In Proc. of the International Conference on Privacy, Security, Risk and Trust, 2011.

9. B. Carminati, E. Ferrari, and M. Guglielmi. SHARE: Secure information sHaring frAmework for emeRgency managemEnt. In Proc. of the 29th International Conference on Data Engineering (ICDE), 2013.

10. D. D. Clark and D. R. Wilson. A comparison of commercial and military security policies. In IEEE Symposium on Security and Privacy, 1987. 
11. J. Cole, J. Derrick, Z. Milosevic, and K. Raymond. Author Obliged to Submit Paper before 4 July: Policies in an Enterprise Specification. In Proc. of the International Workshop on Policies for Distributed Systems and Networks, 2001.

12. J. Crampton and H. Khambhammettu. Delegation and Satisfiability in Workflow Systems. In Proc. of the 13th ACM symposium on Access control models and technologies (SACMAT), 2008.

13. J. Crampton and H. Khambhammettu. On Delegation and Workflow Execution Models. In Proc. of the 2008 ACM symposium on Applied computing (SAC), 2008.

14. J. Crampton and C. Morisset. An Auto-delegation Mechanism for Access Control Systems. In Security and Trust Management. Springer, 2011.

15. D. F. Ferraiolo, D. R. Kuhn, and R. Chandramouli. Role-Based Access Control. Artech House, second edition edition, 2007.

16. A. Ferreira, D. Chadwick, P. Farinha, R. Correia, G. Zao, R. Chilro, and L. Antunes. How to Securely Break into RBAC: The BTG-RBAC Model. In Proc. of the 2009 Annual Computer Security Applications Conference, 2009.

17. A. Ferreira, R. Cruz-Correia, L. Antunes, P. Farinha, E. Oliveira-Palhares, D. W. Chadwick, and A. Costa-Pereira. How to Break Access Control in a Controlled Manner. In Proc. of the 19th IEEE Symposium on Computer-Based Medical Systems, 2006.

18. K. Gaaloul and F. Charoy. Task Delegation Based Access Control Models for Workflow Systems. In Proc. of the 9th IFIP Conference on e-Business, e-Services, and e-Society (I3E), 2009.

19. K. Gaaloul, E. Proper, and F. Charoy. An Extended RBAC Model for Task Delegation in Workflow Systems. In Proc. of the Workshops on Business Informatics Research, 2011.

20. K. Gaaloul, E. Zahoor, F. Charoy, and C. Godart. Dynamic Authorisation Policies for Event-based Task Delegation. In Proc. of the 22nd International Conference on Advanced Information Systems Engineering (CAiSE), 2010.

21. M. B. Ghorbel-Talbi, F. Cuppens, and N. Cuppens-Boulahia. Negotiating and delegating obligations. In Proc. of the International Conference on Management of Emergent Digital EcoSystems (MEDES), 2010.

22. M. B. Ghorbel-Talbi, F. Cuppens, N. Cuppens-Boulahia, D. L. Metayer, and G. Piolle. Delegation of Obligations and Responsibility. In Proc. of the International Information Security and Privacy Conference (SEC), 2011.

23. K. Hasebe, M. Mabuchi, and A. Matsushita. Capability-based delegation model in RBAC. In Proc. of the 15th ACM symposium on Access control models and technologies (SACMAT), 2010.

24. S. Jalali and C. Wohlin. Systematic literature studies: Database searches vs. backward snowballing. In Proceedings of the ACM-IEEE International Symposium on Empirical Software Engineering and Measurement, ESEM '12, pages 29-38, New York, NY, USA, 2012. ACM.

25. B. Kitchenham, O. P. Brereton, D. Budgen, M. Turner, J. Bailey, and S. Linkman. Systematic literature reviews in software engineering - a systematic literature review. Information and Software Technology, 51(1), 2009.

26. S. Marinovic, R. Craven, J. Ma, and N. Dulay. Rumpole: A Flexible Break-Glass Access Control Model. In Proceedings of the 16th ACM symposium on Access control models and technologies, 2011.

27. S. Nurcan. A Survey on the Flexibility Requirements Related to Business Processes and Modeling Artifacts. In Proc. of the Proceedings of the 41 st Annual Hawaii International Conference on System Sciences, 2008.

28. S. L. Osborn and H. Wang. A Survey of Delegation from an RBAC Perspective. Journal of Software, 8(2), 2013.

29. D. Povey. Optimistic Security: A New Access Control Paradigm. In Proc. of the 1999 workshop on New security paradigms, 2000.

30. H. F. Ravi Sandhu, Edward Coyne and C. Youman. Role-Based Access Control Models. IEEE Computer, 29(2), 1996.

31. M. Reichert and P. Dadam. Adept_flex-Supporting Dynamic Changes of Workflows Without Losing Control. J. Intell. Inf. Syst., 10(2), 1998. 
32. M. Reichert, S. Rinderle-Ma, and P. Dadam. Flexibility in Process-Aware Information Systems. In K. Jensen and W. M. Aalst, editors, Transactions on Petri Nets and Other Models of Concurrency II, pages 115-135. Springer-Verlag, Berlin, Heidelberg, 2009.

33. E. Rissanen, B. S. Firozabadi, and M. Sergot. Towards a Mechanism for Discretionary Overriding of Access Control. In Proc. of the 12th International Workshop on Security Protocols, 2004.

34. E. Rissanen, B. S. Firozabadi, and M. Sergot. Discretionary Overriding of Access Control in the Privilege Calculus. In Proc. of the IFIP TC1 WG1.7 Workshop on Formal Aspects in Security and Trust (FAST), 2005.

35. N. Russell, W. M. van der Aalst, and A. H. M. T. Hofstede. Exception Handling Patterns in Process-Aware Information Systems. In International Conference on Advanced Information Systems Engineering (CAiSE), 2006.

36. A. Schaad and J. D. Moffett. Delegation of Obligations. In Proc. of the 3rd International Workshop on Policies for Distributed Systems and Networks, 2002.

37. S. Schefer and M. Strembeck. Modeling Support for Delegating Roles, Tasks, and Duties in a Process-Related RBAC Context. In Proc. of the International Workshop on Information Systems Security Engineering (WISSE), 2011.

38. S. Schefer-Wenzl and M. Strembeck. A UML Extension for Modeling Break-Glass Policies. In Proc. of the 5th International Workshop on Enterprise Modelling and Information Systems Architectures (EMISA), 2012.

39. S. Schefer-Wenzl and M. Strembeck. Generic Support for RBAC Break-Glass Policies in Process-Aware Information Systems. In Proc. of the 28th ACM Symposium on Applied Computing (SAC), 2013.

40. S. Schefer-Wenzl, M. Strembeck, and A. Baumgrass. An Approach for Consistent Delegation in Process-Aware Information Systems. In Proc. of the 15th International Conference on Business Information Systems (BIS), 2012.

41. Q. Shang and X. Wang. Constraints for Permission-Based Delegations. In Proc. of the 8th IEEE International Conference on Computer and Information Technology Workshops, 2008.

42. K. Sohr, M. Kuhlmann, M. Gogolla, H. Hu, and G.-J. Ahn. Comprehensive two-level analysis of role-based delegation and revocation policies with UML and OCL. Information and Software Technology, 54(12), 2012.

43. M. Strembeck and J. Mendling. Modeling Process-related RBAC Models with Extended UML Activity Models. Information and Software Technology, 53(5), 2011.

44. W. M. P. van der Aalst, M. Rosemann, and M. Dumas. Deadline-based Escalation in Process-Aware Information Systems. Decision Support Systems, 43:492-511, March 2007.

45. J. Wainer, P. Barthelmess, and A. Kumar. W-RBAC - A Workflow Security Model Incorporating Controlled Overriding of Constraints. International Journal of Cooperative Information Systems (IJCIS), 12(4), 2003.

46. J. Wainer, A. Kumar, and P. Barthelmess. DW-RBAC: A formal security model of delegation and revocation in workflow systems. Information Systems, 32(3), 2007.

47. B. Weber, S. Rinderle, and M. Reichert. Change Patterns and Change Support Features in Process-Aware Information Systems. In Proc. of the International Conference on Advanced Information Systems Engineering (CAiSE), 2007.

48. H. Zhang and M. A. Babar. Systematic reviews in software engineering: An empirical investigation. Information and Software Technology, 55(7), 2013.

49. L. Zhang, G.-J. Ahn, and B.-T. Chu. A Rule-Based Framework for Role-Based Delegation and Revocation. ACM Transations on Information System Security, 6, 2003.

50. X. Zhang, S. Oh, and R. Sandhu. PBDM: A Flexible Delegation Model in RBAC. In Proc. of the 8th ACM symposium on Access control models and technologies, 2003. 